\title{
Influence of Additives and the Effect of Aging in Modifying Surface Topography of Electrodeposited Copper
}

\section{R. Manu ${ }^{\mathrm{z}}$ and Sobha Jayakrishnan}

Electroplating Metal Finishing Technology Division, Central Electrochemical Research Institute, Karaikudi, Tamilnadu 630006, India

\begin{abstract}
The influence of most common additives used for copper electrodeposition on the physical, microstructure as well as the morphological character of the deposit has been studied. The effect of room-temperature aging on the microstructure of the copper deposit is also discussed in the present work. The X-ray diffraction pattern of the copper deposit has a prominent (111) orientation in addition to (200), (220), and (311) planes typical of copper deposits; the intensity of the planes during aging has a prominent (200) plane; and the ratio of $I_{111}$ to $I_{200}$ changes significantly. The scanning electron microscopy analysis showed that the deposit normally appears to have round or globular features and that there is a change in grain size with respect to a particular additive. From the atomic force microscopy analysis, we can confirm that the average grain size and the roughness of the copper deposits strongly depend on the deposition rate and the type of additive in the bath. There is a change in the grain size and the morphology of the copper deposit due to room-temperature aging. The roughness of the surface increases, and an abrupt shift in the hardness of the coating occurs during aging.

(C) 2009 The Electrochemical Society. [DOI: 10.1149/1.3121212] All rights reserved.
\end{abstract}

Manuscript submitted December 12, 2008; revised manuscript received March 16, 2009. Published April 29, 2009.

With the miniaturization of electronic devices, the connection reliability between integrated circuits and external circuits has become one of the key issues in the electronic packaging industry. Copper has been used as an interconnect material replacing aluminum because of its low resistivity, high electrical conductivity, and electromigration resistance. ${ }^{1-4}$ Various deposition techniques such as chemical vapor deposition, physical vapor deposition, sputter coating, electroless plating, and electroplating are commonly used. Among these methods, electrodeposition is unique and is a versatile technique that is applied for various types of metal and alloy coatings. Copper deposition has received considerable attention with the ever-increasing demand for newer coating techniques for device miniaturization in the electronics industry. ${ }^{5,6}$ Most commonly, an acidic plating bath is used for copper deposition. ${ }^{7,8}$ The electroplating bath usually contains various chemicals as additives in the role of accelerator, suppressor, and leveler for increased plating efficiency. ${ }^{9-11}$ The texture, grain size, surface morphology, and structure of the electrodeposited copper are important for device application, as the properties can affect both performance and reliability. Organic or polymer compounds added to the bath can influence the coating-facilitating uniform deposition with improved metallurgical properties. By understanding the topography and microstructure of the copper deposits obtained from various optimized plating baths, the deposit properties of the coating may be significantly improved.

In the present study, we studied the influence of some common additives, which are already in use, on the mechanical and microstructural properties of the copper deposits. Electrodeposited copper is known to undergo self-annealing, which is a process of recrystallization proceeding at room temperature. Electrodeposited films can be of a deformed state containing numerous vacancies with various growth-related defects introduced during their deposition. Here recrystallization can result over time from several hours to several years after electrodeposition at room temperature. ${ }^{12-14}$ Due to this, there can be a transformation in the crystal structure to minimize the strain of the deposit. This could alter the microstructure and other relevant properties of the deposit, leading to potential problems in its use for specific applications. Although reports are available on the change in ductility and other properties of the deposit during aging, the change in microstructure, topography, etc., of the deposit is not well illustrated. ${ }^{15}$ There are reports on the influence of various additives on the room-temperature recrystallization of electrodeposited copper using X-ray diffraction (XRD) and resistance measurements. $^{16}$

In the present study, XRD, scanning electron microscopy (SEM),

${ }^{\mathrm{z}}$ E-mail: manupanikker@gmail.com and atomic force microscopy (AFM) techniques were used to study the effect of additives on the microstructure and the topographical feature of copper deposits. The properties of the copper deposits such as hardness, thickness, and roughness were determined and compared. Cyclic voltammetric (CV) studies of the copper deposits in various plating baths were studied. The change in the surface topography of the copper deposits after room-temperature aging and its effect on the mechanical properties of the deposits were investigated. The nanometer changes in the grain size and the corresponding shift in the surface roughness of the deposit, as revealed from AFM analysis, reflect that the microstructural character was modified during the room-temperature aging of the deposit, affecting changes in the resistance and other relevant properties of the deposit.

\section{Experimental}

A thin copper sheet of $0.5 \mathrm{~mm}$ thickness was used as the substrate for the present study. In the electronic packaging process, the base substrate was a copper-clad sheet over which the copper pattern was developed, so considering this for the present study we used a thin copper foil for the electrodeposition process. The size of the copper substrate was $500 \times 100 \times 0.5 \mathrm{~mm}$. The copper substrate was polished with different grade emery paper up to mirror finish appearance. The substrate was then precleaned by various processes before electrodeposition. The substrate was degreased with acetone and then cathodically polarized in alkaline cleaner for 2 min under a current strength of $2 \mathrm{~A} / \mathrm{dm}^{2}$. The alkaline cleaner had the following composition: $20 \mathrm{~g} / \mathrm{L}$ sodium carbonate, $7 \mathrm{~g} / \mathrm{L}$ sodium hydroxide, and $9 \mathrm{~g} / \mathrm{L}$ sodium hypophosphate. The substrate was washed thoroughly with distilled water and then dipped in $5 \% \mathrm{HCl}$ solution for $10 \mathrm{~s}$. The substrate was rinsed with distilled water before plating. The compositions of the various constituents in the bath are given in Table I. All the chemicals were of analytical grade, and millipore-Q water was used for making solutions. For the present study, poly(ethylene glycol) (PEG) of $8000 \mathrm{Mw}$ was selected as this is commonly used for copper electrodeposition from sulfate baths and is well studied for its filling efficiency. Various bath components were

\begin{tabular}{lcccc}
\multicolumn{5}{l}{ Table I. The composition of the plating bath. } \\
\\
Bath ingredients & A & B & C & D \\
\hline Copper sulfate (g/L) & 90 & 90 & 90 & 90 \\
Sulfuric acid (g/L) & 120 & 120 & 120 & 120 \\
PEG (ppm) & - & - & 200 & 200 \\
Chloride $\left(\mathrm{Cl}^{-}\right)(\mathrm{ppm})$ & - & 50 & - & 50
\end{tabular}


individually added to the plating bath through dilution from the stock solution prepared with properly concentrated contents of these additives. The temperature of the plating solution was maintained at $28^{\circ} \mathrm{C}$. The current density was maintained at $3 \mathrm{~A} / \mathrm{dm}^{2}$, and the plating time was 15 min. Hardness, thickness, and roughness were determined as per standard test methods. The hardness of the copper deposit was tested using Everone model MH-6, applying a load of 10 gf, and was expressed in Vickers hardness number (HV). The roughness of the deposit was measured by a Mitutoyo model SJ-301 surface roughness tester having a sensitivity of $0.01 \mu \mathrm{m}$.

The change in cathode potential during electrodeposition was recorded with reference to the saturated calomel as the reference electrode. CV analysis of the copper deposit with respect to various plating baths was done using Autolab PGSTAT 30 model. CV analysis was conducted in the potential range of -0.75 to $+0.75 \mathrm{~V}$ to examine the effects of PEG and $\mathrm{Cl}^{-}$on copper deposition and dissolution. A three-electrode system was used, where Pt with an exposed surface area of $0.1 \mathrm{~cm}^{2}$ served as the working electrode and $\mathrm{Pt}$ with a larger area was the counter electrode. A saturated calomel electrode (SCE) served as the reference electrode, and the scan rate was $10 \mathrm{mV} / \mathrm{s}$. All the potentials in the present paper refer to the potentials vs SCE.

The surface morphology of the copper deposit was examined by SEM under different magnifications. A Hitachi scanning electron microscope (model S-3000 H) was used for the purpose. The electrodeposited samples were taken for SEM examination without any pretreatment. AFM studies were also performed to view the threedimensional topography of the deposit, and these were compared with respect to various additives. The topographic analysis of the electroplated samples was performed using a commercial AFM (molecular imaging, Picoscan 2100) instrument in the contact mode. A phosphate $(n)$-doped silicon coated cantilever (with a force constant of -0.05 to $3 \mathrm{~N} / \mathrm{m}$ ) was used for imaging. The height mode was used to scan the surface. The system automatically kept the force, and hence the distance between the tip and the surface remained constant. The AFM images were recorded over a scan area of 2 $\times 2$ or $5 \times 5 \mu \mathrm{m}$. The mean square roughness $\left(R_{\mathrm{a}}\right)$, which is defined as the standard deviation of the surface height profile from the mean height, is the most commonly reported measurement of surface roughness and is given by $R_{\mathrm{a}}=1 / N \Sigma\left[Z_{i}-Z\right]$, where $Z$ is defined as the sum of the height values divided by the number of data points $(N)$ in the profile and $Z_{i}$ is the height of the $i$ th pixel. The change in the crystallographic orientation and the preferential plane of the copper deposit was identified by XRD analysis. The XRD pattern of the coating was analyzed by using a PANanalytical machine of model PW3040/60 X'pert PRO. The data were processed using PCAD software to identify the crystal structure. The grain size was calculated by Scherer's formula. The modification in the grain structure during room-temperature aging and the resulting change in the properties of the copper deposits were also compared. X-ray photoelectron spectroscopy (XPS) of the copper deposit was also done using Thermoscientific Multilab-2000, having Mg $\mathrm{K} \alpha$ as the source to detect the trace element in the deposited sample.

\section{Results and Discussion}

Electrochemicalcharacterization.-Cathodic potential change with plating time during copper deposition.- Figure 1 shows potential-time curves for the copper deposition at a fixed current strength in an optimized bath with various additives. The influence of additives on metal (copper) deposition begins with the interaction with the electrode surface. Voltages at the initiation of deposition were more polarized in the copper deposit obtained in the presence of additives such as PEG and $\mathrm{Cl}^{-}$than in the deposit without any additive. This could be due to the rapid adsorption of additives during the initiation of deposition; this can also be due to the suppression of copper plating by additives. As plating continued, the cathodic potential decreased and depolarization was observed. In the copper deposit without any additive, a depolarization behavior was

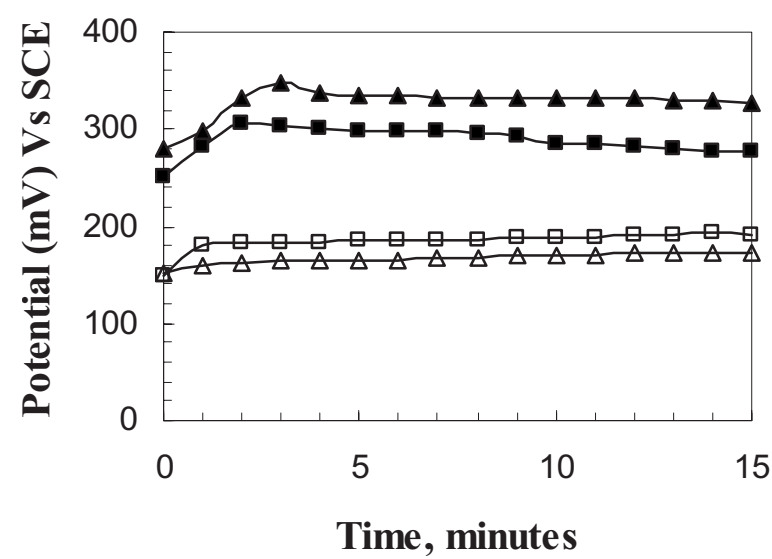

Figure 1. Potential as a function of time during galvanostatic deposition of copper from different baths. $\triangle$, copper without any additive; $\square, \mathrm{Cu}+\mathrm{Cl}^{-}$; $\boldsymbol{\square}, \mathrm{Cu}+\mathrm{PEG} ; \boldsymbol{\Delta}, \mathrm{Cu}+\mathrm{PEG}+\mathrm{Cl}^{-}$.

not observed, and when $\mathrm{Cl}^{-}$was present together with PEG there was appreciable depolarization in the curve. Although the concentration of $\mathrm{Cl}^{-}$was less in the plating bath, i.e., $\sim 50 \mathrm{ppm}$, the presence of chloride in the copper deposit was confirmed by XPS analysis (Fig. 2). This reveals that the trace amount of chloride also got incorporated into the deposit. Along with $\mathrm{Cl}^{-}$ions, $\mathrm{PEG}$ established a polarized film at the surface, and during the progress of the deposition the depolarization effect decreased, as is clear from the graph. It is reported that in the leveler-containing additive systems, rapid depolarization was observed, which may lead to a variation in deposit thickness in copper plating. ${ }^{17}$ The presence of chloride ion would accelerate the copper deposition reaction and would decrease the cathodic potential. The inhibiting effect over the cathode surface by the formation of PEG-Cu${ }^{+}$and PEG- $\mathrm{Cu}^{2+}$ complexes with $\mathrm{Cl}^{-}$ could result in the widening of the potential range and could have a subsequent effect on the deposition rate. After 5-10 min of plating, the potential was almost steady.

$C V$ studies.- In all cases two peaks appear irrespective of the additives, in the forward and reverse scan of the cyclic voltammogram (Fig. 3). The peaks in the forward scan lie within the potential range of -0.2 to $-0.5 \mathrm{~V}$ in the positive sweep (peak 1) and between +0.2 and $+0.5 \mathrm{~V}$ in the negative sweep (peak 2). But the positive peak

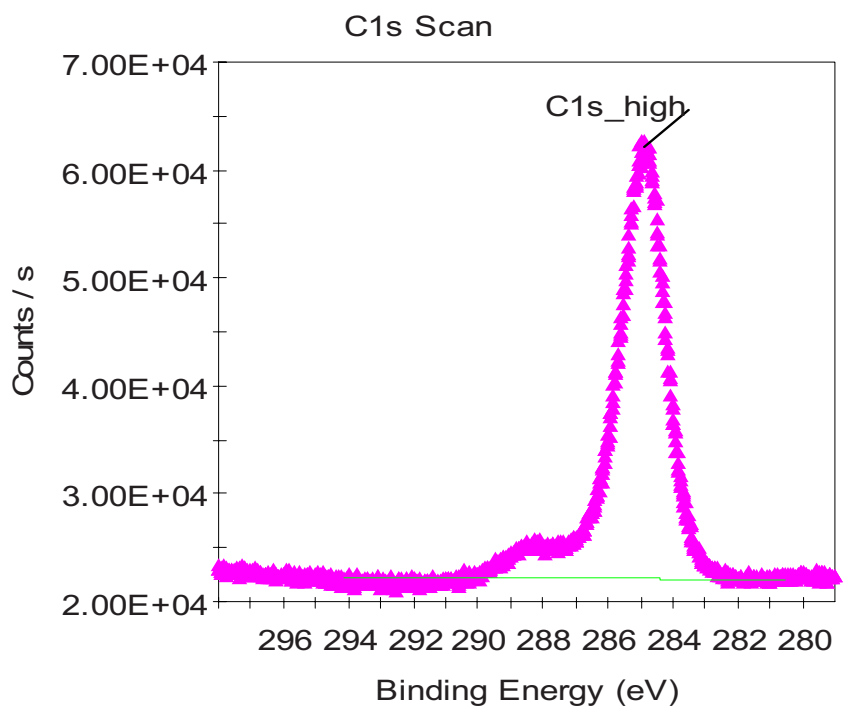

Figure 2. (Color online) XPS analysis of the copper deposit showing the characteristic peak for chloride. 


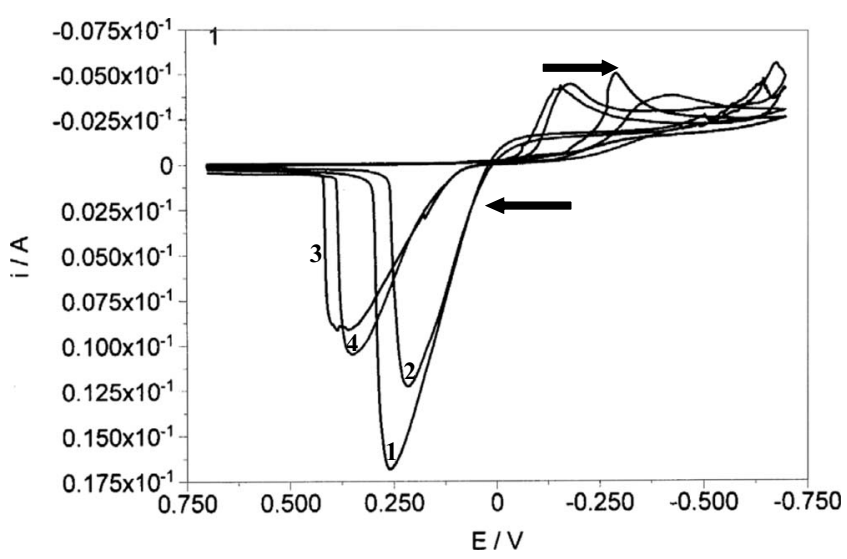

Figure 3. Cyclic voltammogram of the copper deposit with various bath compositions: (1) Copper without additive, (2) $\mathrm{Cu}^{+} \mathrm{Cl}^{-}$, (3) $\mathrm{Cu}+\mathrm{PEG}$, and (4) $\mathrm{Cu}+\mathrm{PEG}+\mathrm{Cl}^{-}$.

potential is shifted to more negative values when additives are incorporated into the bath, and this is prominent in the bath containing $\mathrm{PEG}+\mathrm{Cl}^{-}$. The area of the peak also increases in the forward scan. This can be ascribed to the difference in the hydrogen evolution rate during the progress of the deposition. In the copper deposit obtained from the pure copper bath and the $\mathrm{Cl}^{-}$-containing bath, there is hysteresis, and this corresponds to irreversible changes in surface chemistry during deposition and dissolution processes. This is not the case with respect to the PEG-containing bath, where there is no hysteresis in the cyclic voltammogram, indicating that the surface chemistry of the additive system does not change during the reaction. From the voltammogram, it can be inferred that peak 1 reaction causes an increase in the mass of the electrode in the anodic current region due to the adsorption of the complex $\mathrm{Cu}^{+} \cdot \mathrm{Cl}^{-} \cdot \mathrm{PEG}$, and the peak 2 reaction leads to a decrease in the mass of the cathode electrode in the cathodic current region where it is shifted to more positive values with PEG addition, reducing $\mathrm{Cu}^{+} / \mathrm{Cu}^{2+}$ to copper. The area of the peak in the reverse scan was also reduced with PEG addition, showing a change in the dissolution mechanism of the complex. From this we can infer that in the presence of $\mathrm{Cl}^{-}$, PEG forms an adsorbed monolayer to the cathode surface, which controls the deposition rate.

$X R D$ analysis of the copper deposit.- The role of additives is not limited to uniform filling but also extends to the incorporation of impurities into the plated copper films and a subsequent change in microstructure. The texture, as well as the microstructure of the deposit, was characterized by various instrument techniques. The XRD scan data of copper deposits with and without additives before and after aging are compared in Fig. 4A and B. The peak intensity of the (111) plane was higher compared to the (200) plane, irrespective of additive modification. The intensity of the (111) peak was greater for the copper deposit without any additive compared to other types of deposit. Also, in the pure copper substrate without any deposition, the prominent peaks were (111) and (200). The peak intensities of (220) and (311) were low for the pure copper substrate when compared to the substrate with a copper deposit. This clearly shows that the crystallographic structure of the copper deposit is mostly (111) oriented, subjected to some marginal changes with reference to various additives. The prominence of the (111) plane could be due to the lower surface energy of the plane and is aligned parallel to the surface. The (200) peak intensity was high for the copper deposit obtained from the pure copper bath and the $\mathrm{Cl}^{-}$-containing bath, whereas for the deposit obtained from the PEG-containing bath, the (200) peak was less. The ratio of $I_{111} / I_{200}$ was almost the same for the pure copper deposit and for the deposit obtained from the PEGcontaining bath. This ratio significantly changed when $\mathrm{Cl}^{-}$was added to the system. This can be ascribed due to the uniform depo- sition in the presence of halide ions. In addition to (111) and (200) peaks, there is a prominence of (220) and (311) peaks. From this we can infer that the presence of additives has a significant role on the texture of the copper deposit. The grain size of the deposit was calculated using Scherer's formula

$$
T=\frac{0.9 \lambda}{B \cos \theta}
$$

where 0.9 is the Scherer constant, $\lambda$ is the wavelength, $B$ is the full width at half-maximum value, and $\theta$ is the angle. The crystallite size of the copper deposit was calculated as per the equation before and after aging. The average grain size of the crystallites of the copper deposit from the pure copper bath showed a marginal increase after aging compared to the copper deposit with additive modification. With the addition of PEG, the average grain size of the copper deposit decreased. This could be due to a better grain refinement and the nucleation growth of the deposit during deposition. The presence of additives induces a progressive growth pattern from the initial nucleation sites. The controlled growth pattern ensures uniformity in grain size and grain morphology. The presence of PEG improves the hydrogen evolution rate, thereby reducing the grain boundary voids that may be found due to hydrogen gas evolution during electrodeposition. The intensities of various peaks before and after the aging process were compared. XRD analysis of the copper deposit was performed after room-temperature aging. The XRD profile shown in Fig. 4C reveals that the crystallographic structure of the deposit obtained from the PEG-containing bath changed significantly during aging. In all cases the peak intensity was greater for the (111) plane in all copper deposits after room-temperature aging with a slight increase in the intensity of the (200) plane. This may be assigned as the (111) oriented grains have the lowest surface energy for any face-centered cubic systems. In the thin-film deposit, there can be voids or vacancies, and during recrystallization these sites will be rearranged, stabilizing the surface energy. ${ }^{12}$ For the PEGcontaining bath there is a significant increase in all planes during the aging process. The ratio of $I_{111} / I_{200}$ was changed after aging for the copper deposit obtained from the PEG-containing bath. This can be ascribed to the change in the orientation of the randomly distributed grains and the migration of excess vacancies present in the freshly deposited surface. These changes observed for copper deposits during aging can be ascribed to the fact that electrodeposited copper films have a substantial amount of randomly oriented grains, and these grains serve as source materials for the growth of (111) and (200) planes during aging. ${ }^{13,18}$ There may be anisotropic grain growth that leads to change in the preferred crystallographic orientation upon self-annealing. This may lead to changes in the microstructure of the copper deposit, effecting changes in the texture of the plane during room-temperature aging.

Surface morphological analysis. - The modifications in the surface morphology of the copper deposit under different bath formulations were examined by SEM (Fig. 5). The various morphological features of the surface were illustrated based on the deposit grain size and shape. For a blank copper deposit, a nonuniform surface having a larger grain size was observed. The grain size and shape were not uniform and were not well distinguished from each other. There are large and small grains and they have a large grain boundary volume compared to other types of deposits. But in the copper deposit with $\mathrm{PEG}+\mathrm{Cl}^{-}$, the grain size $(0.4 \mu \mathrm{m})$ was small compared to the other two types of deposits. Slight agglomerations occur over the entire surface. The deposit was smoother. The smaller grain size is consistent from the previous finding that nucleation during electrodeposition changes from instantaneous to progressive in the presence of PEG $+\mathrm{CI}^{-} .5$ But in the copper deposit with PEG alone, the surface was slightly rough with uniform grain size. The grains resembled a cubical shape with an average grain size of $\sim 0.7 \mu \mathrm{m}$. It is well known that organic additives added in small quantities can alter the texture as well as the metallurgical properties of the copper deposit. ${ }^{19-21}$ The adduct, PEG-Cl- formed gets adsorbed onto metal 


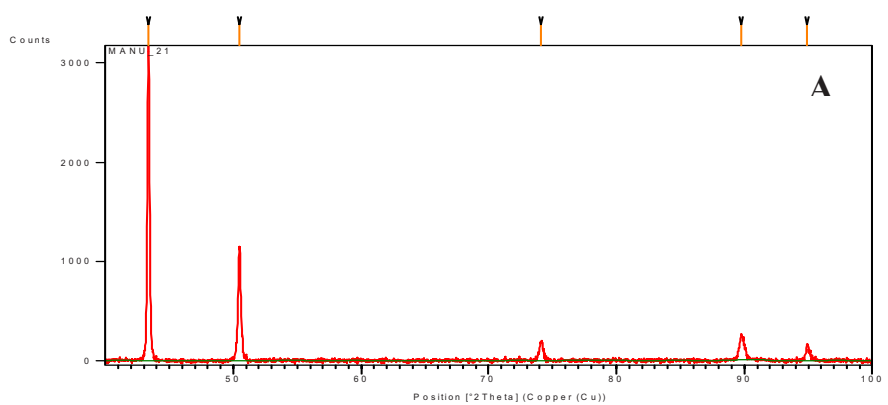

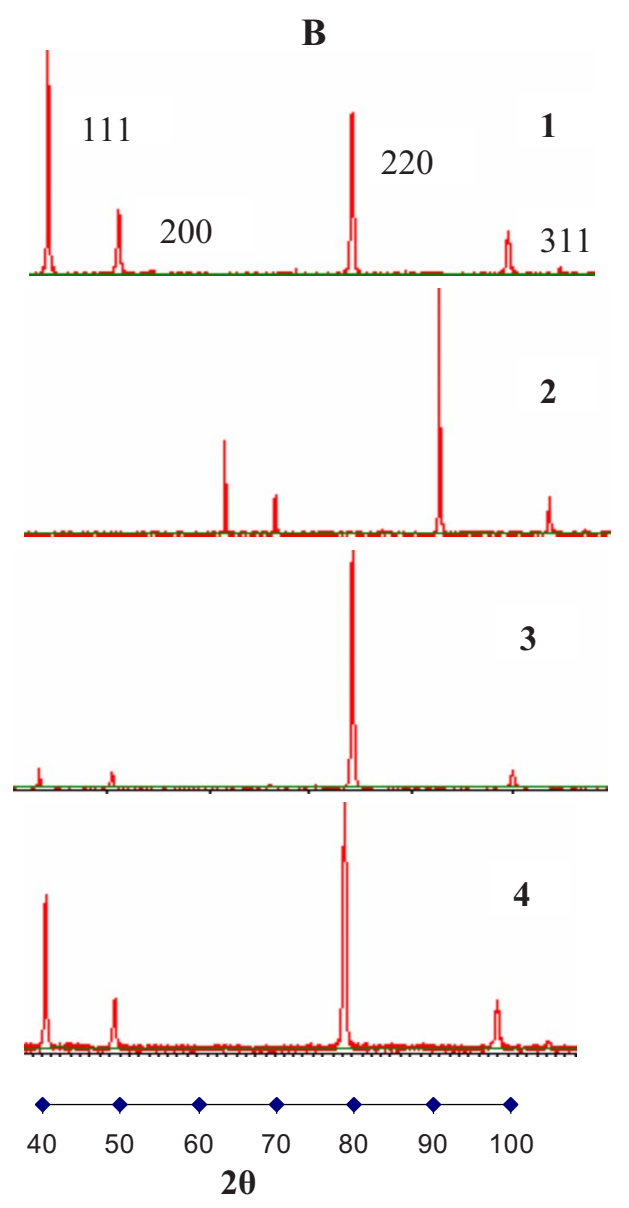

20

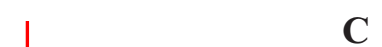

C

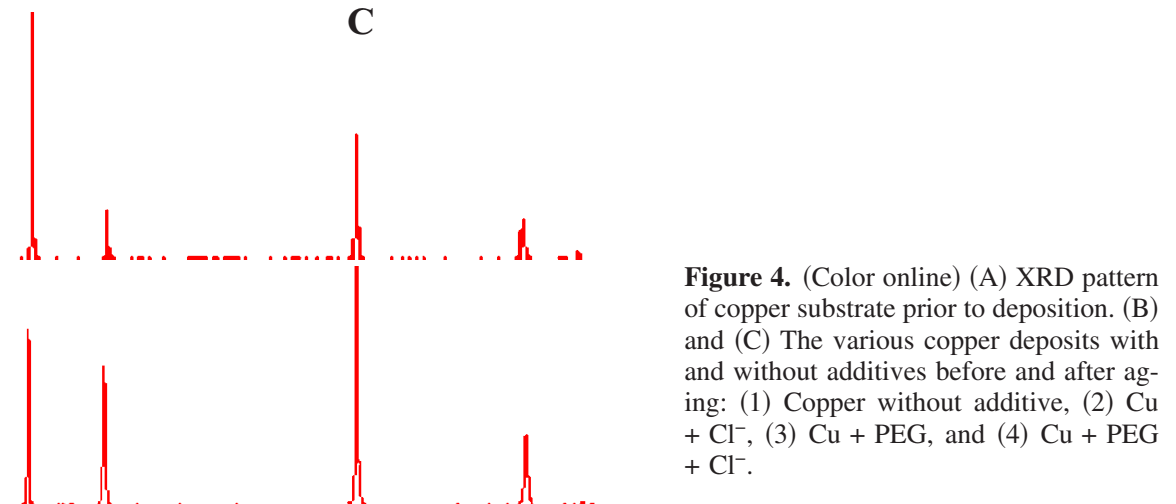

surface in the form of a monolayer in the presence of $\mathrm{Cu}^{+}$. This adsorptive behavior implies that the coverage of the PEG- $\mathrm{Cu}^{+}-\mathrm{Cl}^{-}$ complex affects the inhibition of copper deposition. Through the ordered and abundant defects in the adsorbed layer, nucleation results, thereby facilitating the gradual growth of alloy layers. This facilitates the formation of a more compact and adherent coating with void-free surface morphology.

The AFM images of the various copper deposits are compared in Fig. 6A and B. The topography of the copper surface without any deposition shows an almost smooth and uniform surface feature. But in the copper deposit with and without a $\mathrm{Cl}^{-}$-containing bath, agglomeration occurs and the grain size is larger. Agglomeration occurs, and the peak height varies within 500-600 nm. The deposition carried out in the presence of PEG $+\mathrm{Cl}^{-}$as additives was smoother and uniform with minimum peaks and valleys over the entire surface. Surface-enhanced Raman spectroscopy clearly tells us that the adsorption of PEG on the copper surface is associated with the presence of $\mathrm{Cu}^{+}$and $\mathrm{Cl}^{-}$, where $\mathrm{Cu}^{+}$serves as an intermedium to link
PEG and $\mathrm{Cl}^{-}$, and $\mathrm{Cl}^{-}$acts as a dynamic anchor to immobilize the PEG-Cu $-\mathrm{Cl}$ complex onto the as-deposited copper. ${ }^{22}$ It agrees with the report that the addition of PEG $+\mathrm{Cl}^{-}$in the plating bath could influence the deposition character of the copper deposit and enhance the void-free filling having a uniform surface feature. ${ }^{23}$ In the deposit with PEG alone, the surface appears to have some valleys with height varying from 200 to $300 \mathrm{~nm}$. In the presence of PEG alone, there is an increase in the roughness of the copper deposit resembling a pyramidal structure. From this it is clear that with respect to various additives there can be a modification in the surface topography and the microstructure of the copper deposit. Through optimizing the bath condition and other parameters, the nature and the property of the copper deposit can be improved.

Physical properties of the deposit.- Properties such as hardness, thickness, and roughness of the copper deposits obtained with respect to various additives are compared in Table II. The hardness of the coating shows a gradation with various additives. The hardness 
A
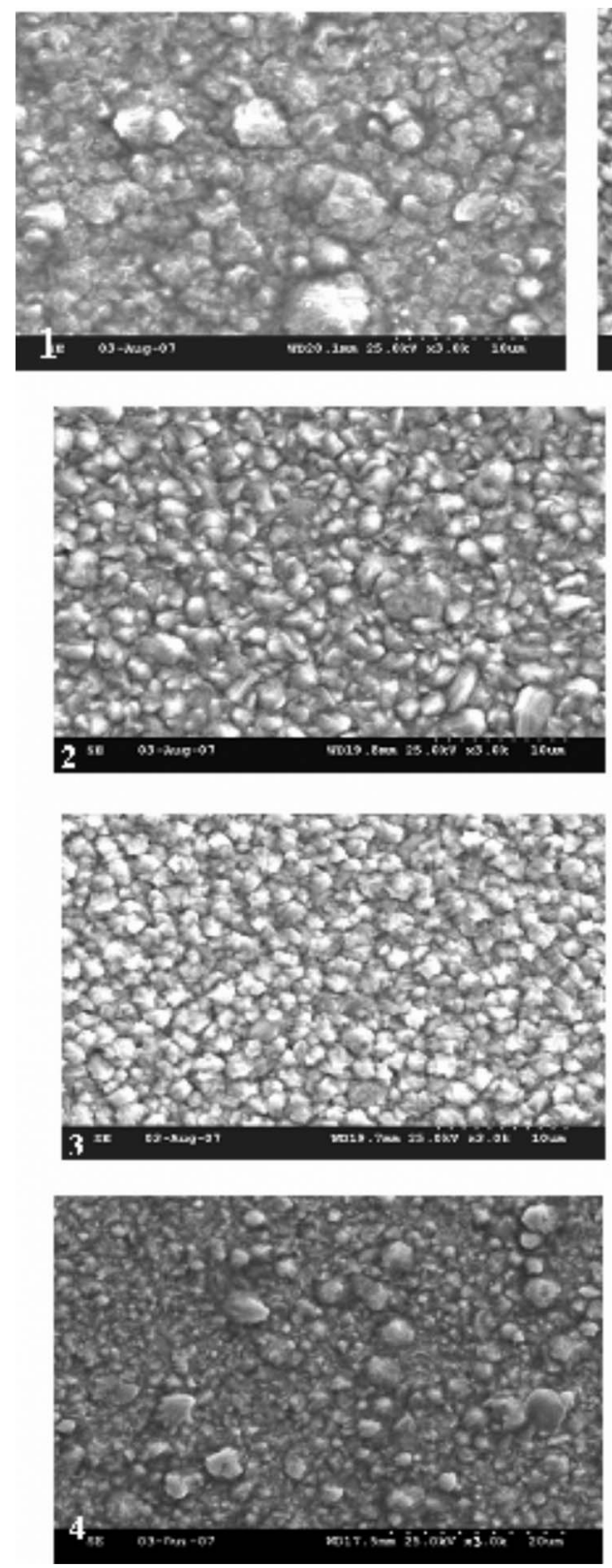

B
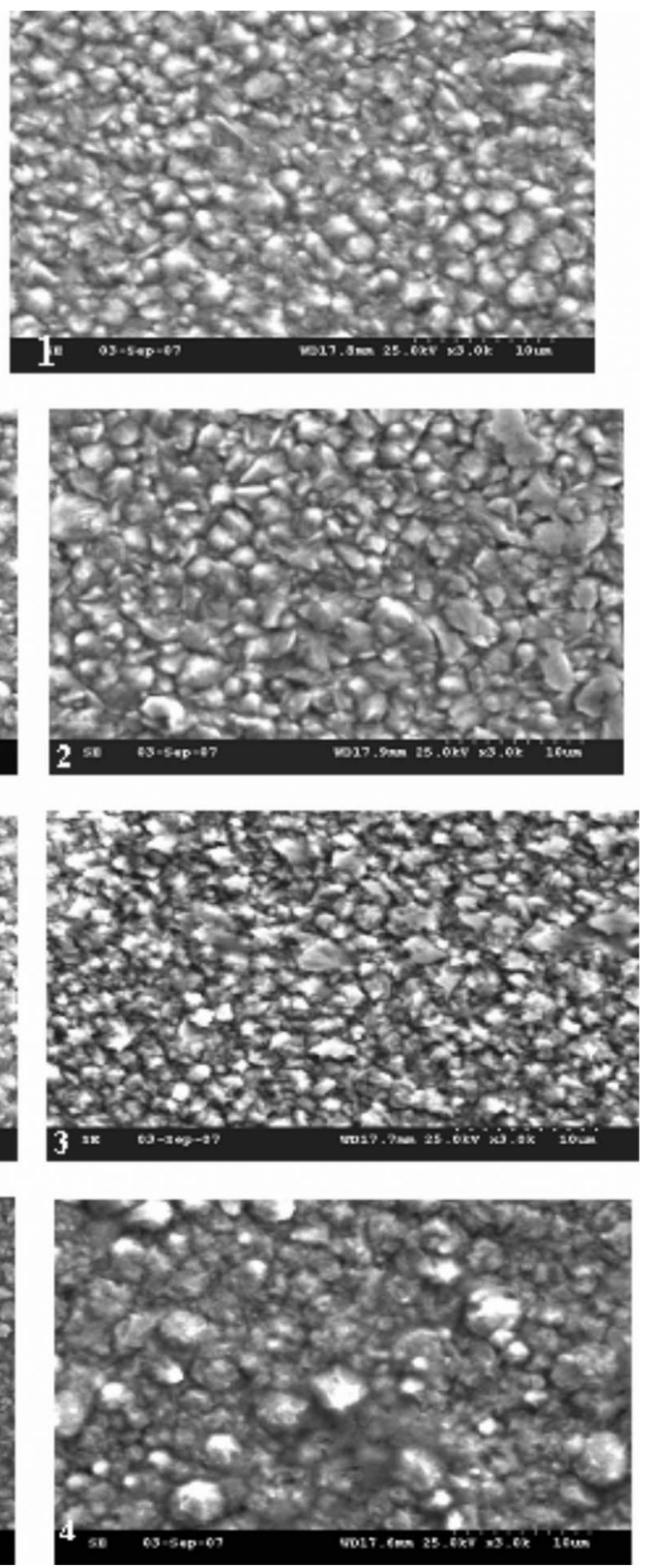

Figure 5. (A) and (B) SEM analysis of the copper deposit before and after aging: (1) Copper without additive, (2) $\mathrm{Cu}$ + PEG, (3) $\mathrm{Cu}+\mathrm{Cl}^{-}$, and (4) $\mathrm{Cu}+$ PEG $+\mathrm{Cl}^{-}$. value of the copper deposit with $\mathrm{PEG}+\mathrm{Cl}^{-}$was greater compared to the other three types of coating. The slightly greater hardness observed could be attributed to the smaller grain size and the inhibiting effect of PEG, forming a complex that controlled the rate of deposition, and forming a more compact and uniform deposit. The grain size is generally recognized as an important factor affecting mechanical characteristics such as hardness and ductility. A decrease in grain size has an effect on hardness. Fine-grained deposits have high ductility and hardness. The hardness of the pure copper deposit is lower compared to the others, as it is evident that the coarsegrained structure makes the surface less ductile and the hardness lower. The thickness of the copper deposits showed abrupt changes, varying between 7 and $8 \mu \mathrm{m}$. The copper deposit obtained from the $\mathrm{PEG}+\mathrm{Cl}^{-}$-containing bath had an $8 \mu \mathrm{m}$ thickness. The roughness of the deposit showed changes with respect to various additives in the plating bath. Deposits obtained from the bath containing only PEG have higher roughness compared to the deposit from the bath containing PEG and $\mathrm{Cl}^{-}$and the bare copper plating. There are reports on roughness increase for a copper deposit with a PEG- containing bath. ${ }^{24}$ This observation is supported by the twodimensional appearance of the deposit taken by AFM, where the mean height varies from 200 to $400 \mathrm{~nm}$ in the copper deposit with only a PEG addition. The copper deposit with a PEG additive appears dull with a salmon red color surface. The lower roughness in the PEG $+\mathrm{Cl}^{-}$can be attributed to the fine-grained structure and the uniform deposit. Although PEG is a weak inhibitor, the presence of $\mathrm{Cl}^{-}$facilitates the polymer adsorption process by forming a complex with $\mathrm{Cu}^{+}$ions through the oxygen backbone of the polymer. Through electrostatic interaction, this complex would be more tightly attached to the copper surface when $\mathrm{Cl}^{-}$is present. Hence this could benefit in forming a more regular structure with a coarsegrained deposit. The thickness of the copper deposits under identical deposition conditions was almost the same with a slight increase from the PEG added bath. The hardness and roughness of the copper deposit showed marginal changes during room-temperature aging. Hardness change can be attributed to the change in the grain morphology of the deposit where individual grains merge to reduce the strain associated within the deposit. The hardness increase was 
A

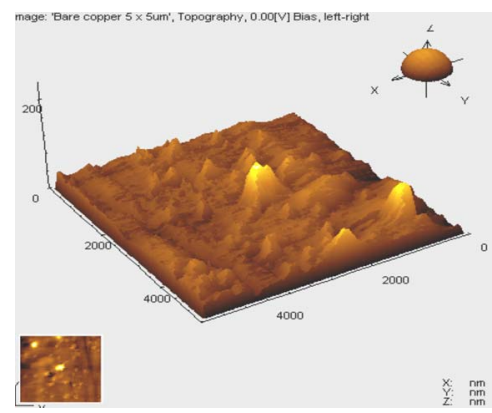

B
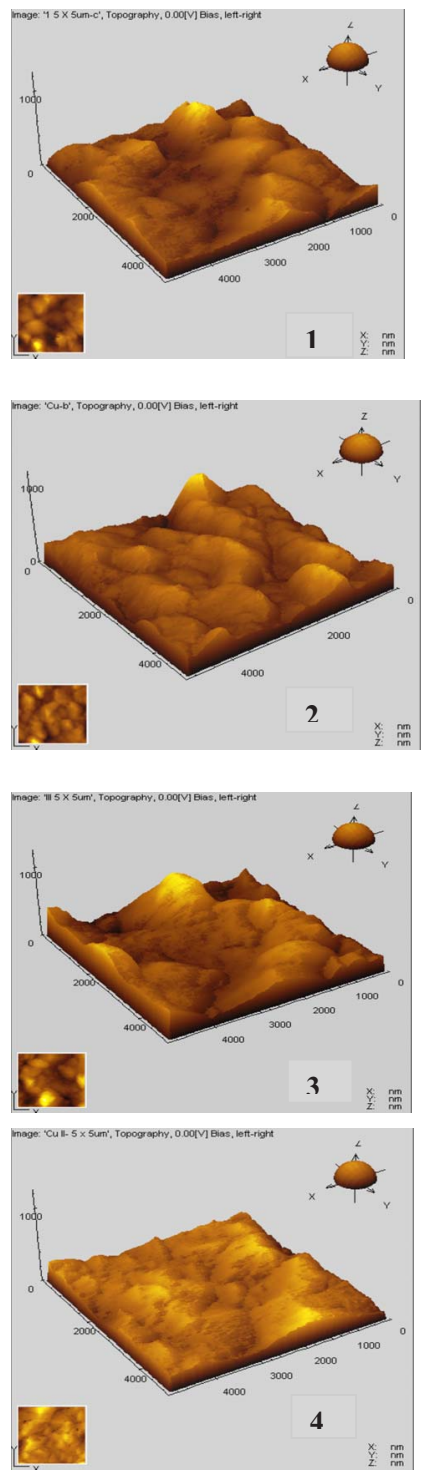

C
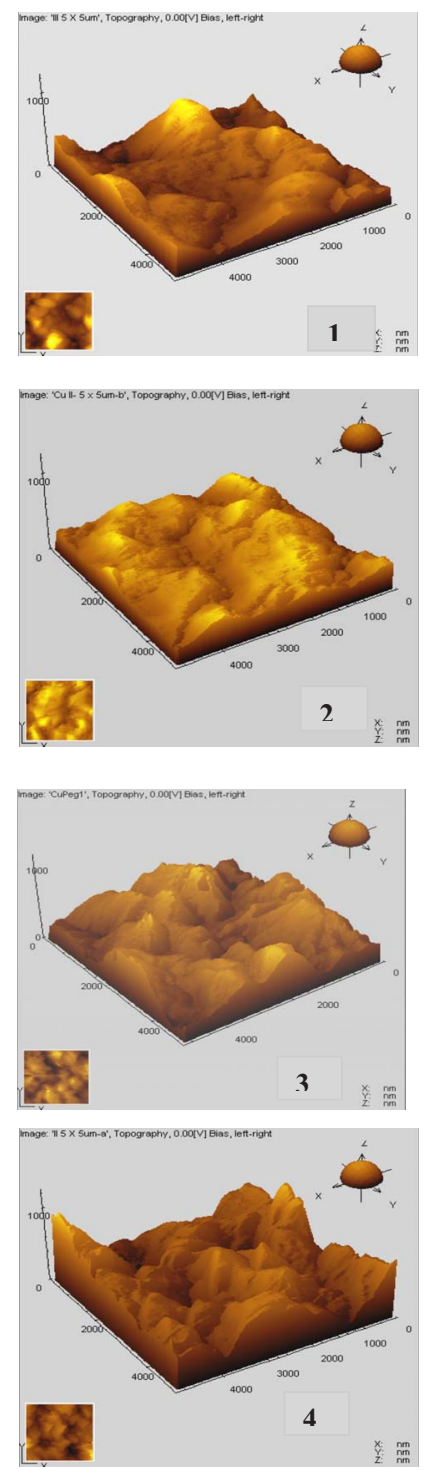

Figure 6. (Color online) (A) AFM analysis of pure copper substrate prior to deposition. (B) and (C) Copper deposit before and after aging: (1) Copper without additive, (2) $\mathrm{Cu}+\mathrm{Cl}^{-}$, (3) $\mathrm{Cu}+\mathrm{PEG}$, and (4) $\mathrm{Cu}+\mathrm{PEG}+\mathrm{Cl}^{-}$.

greater for the $\mathrm{PEG}+\mathrm{Cl}^{-}$-containing bath, where the recrystallization phenomenon is related to the impurities that are trapped in the copper deposit during plating. The roughness of the copper deposit changed abruptly with room-temperature aging although the rough- ness of the copper deposit obtained from the PEG $+\mathrm{Cl}^{-}$-containing bath was lower compared to other types of deposits.

Effect of room-temperature aging.- The change in the morphology of the copper deposit with respect to room-temperature aging was compared by AFM and SEM analyses of the copper deposit. The roughness of the copper deposit was slightly increased after aging, showing a variation from initial values. The SEM images of the copper deposit showed that an abrupt change occurs in the morphology during room-temperature aging over the entire surface (Fig. $5 \mathrm{~B})$. The grain size of the deposit from the pure copper bath after aging was slightly decreased, and the shape was not uniform. This could be due to the lack of void-free filling of copper over the substrate, and during aging a rearrangement-forming surface occurs with a rougher feature. In the copper deposited from the PEGcontaining bath, the grains have no regular shape after aging and without any specific pattern. The individual grains coalesced, forming bigger grains, and the grain size was also not uniform. These modifications can be attributed to the vacancy/surface defect annihilation during aging. SEM images of the copper deposit from the $\mathrm{PEG}+\mathrm{Cl}^{-}$additive revealed some rounded edges composed of an agglomeration of spheroids. The change in the morphology of the copper deposit during aging is not only due to the surface oxidation of the deposit but also to the point defects in the crystal lattice of the deposit. In the thin-film deposition, it is reported that there can be a change in density from the gaseous state to the solid state, which can lead to the incorporation of defects such as vacancies and voids. ${ }^{15,25}$ These defects were annihilated gradually over long-term roomtemperature aging, causing changes in the surface morphology of the deposit and leading to a change in the properties of the deposit as well. In all cases we could observe a modification in morphology during aging, and it was pronounced in the copper deposit obtained from the PEG $+\mathrm{Cl}^{-}$addition. This could also be due to the incorporation of more contaminants that resulted from the reaction of bath additives forming secondary products. Due to this the surface energy of the deposit is high, and during the aging process this is annihilated. The AFM images of the copper deposit after aging also show some remarkable changes in deposit morphology (Fig. 6C). The surface appears to have some peaks and valley region in the copper deposited from PEG- and $\mathrm{Cl}^{-}$-containing baths. The change was more pronounced with respect to the copper deposit obtained from the bath containing PEG only. This change in deposit morphology can be attributed to the surface oxidation followed by roomtemperature recrystallization of the copper deposit during aging. In the freshly deposited films, there are unstable vacancies and this can migrate to various sinks during room-temperature aging. Electrodeposited $\mathrm{Cu}$ films can have a substantial amount of randomly oriented grains that serve as source materials for growth of different textures during recrystallization. ${ }^{12}$ The change in the microstructure of the copper deposit results from recrystallization during self-annealing, effecting a significant modification in the properties during aging. The modification in the surface feature is also governed by the impurities associated within the deposit during plating. Due to this, the recrystallization phenomenon can be different with respect to various copper deposits, where there can be a decrease in the concentration of defects, viz., vacancies and dislocations and the misalignment of adjacent grains. These dramatic changes caused during aging modifies the surface topography and also some beneficial properties of the copper deposit. The change in the grain size of the copper deposit is compared in Fig. 7. The grain size was calculated by Scherer's formula. The size of the grain appears to be narrowly distributed with an average diameter of about $0.8-1 \mu \mathrm{m}$, slightly greater when compared before aging. The roughness of the deposit can be compared with grain size, where the smooth films have large grains, while the rough films consist of small grains. The above comparison of SEM and AFM images of the copper deposit shows some characteristic changes occurring during room-temperature aging and its subsequent effect on roughness and other properties of the copper deposit. 


\begin{tabular}{|c|c|c|c|c|c|}
\hline Sample & $\begin{array}{c}\text { Hardness }(\mathrm{HV}) \\
\text { before aging }\end{array}$ & $\begin{array}{l}\text { Thickness } \\
(\mu \mathrm{m})\end{array}$ & $\begin{array}{l}\text { Roughness } \\
\text { before aging } \\
\quad(\mu \mathrm{m})\end{array}$ & $\begin{array}{l}\text { Hardness (HV) } \\
\text { after aging }\end{array}$ & $\begin{array}{l}\text { Roughness } \\
\text { after aging } \\
\quad(\mu \mathrm{m})\end{array}$ \\
\hline Copper & 150 & 7.0 & 0.21 & 160 & 0.28 \\
\hline Copper $+\mathrm{Cl}^{-}$ & 168 & 7.5 & 0.24 & 165 & 0.31 \\
\hline Copper + PEG & 190 & 7.8 & 0.24 & 203 & 0.32 \\
\hline
\end{tabular}

\section{Conclusions}

The hardness, roughness, and microstructure of the copper deposit were studied as a function of various additives. The presence of additives in the plating bath had a significant influence on the surface topography as well as on the various properties of the coating. The presence of both PEG and $\mathrm{Cl}^{-}$in the bath benefited in forming the copper deposit with a smoother surface feature with a void-filled copper deposit. The mobility of voids/vacancies in the as-deposited substrate changes the surface topography of the copper deposit during long-term room-temperature aging. This can affect the microstructure as well as the physical properties of the copper deposit, as revealed from the surface topographical analysis. The change in the microstructure of the deposit during aging is not only due to the presence of defects in the deposit but also to the impurity level associated with different types of deposit. The change in grain structure and crystallographic orientation due to room-temperature aging could also affect some relevant properties such as the roughness and hardness of the deposit.

\section{Acknowledgments}

The authors are grateful to Professor A. K. Shukla, Director, Central Electrochemical Research Institute, for his encouragement and for extending facilities to complete this work. R.M. acknowl-

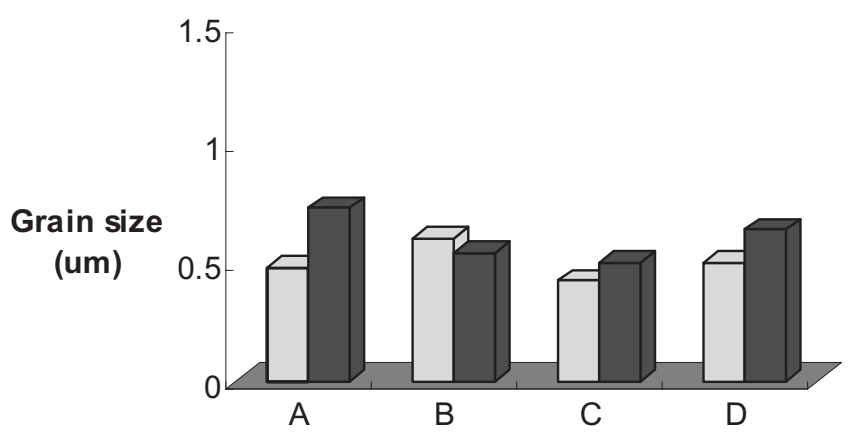

Figure 7. Grain size dependence of the copper deposit with various additives before and after aging: (A) Copper without additive, (B) $\mathrm{Cu}^{-} \mathrm{Cl}^{-}$, (C) $\mathrm{Cu}$ $+\mathrm{PEG}$, and (D) $\mathrm{Cu}+\mathrm{PEG}+\mathrm{Cl}^{-}$. Before aging: light graph; after aging: dark graph. edges CSIR, New Delhi, for the financial support to carry out this research work under the research associateship scheme.

Central Electrochemical Research Institute assisted in meeting the publication costs of this article.

\section{References}

1. C.-C. Hu and C.-M. Wu, Surf. Coat. Technol., 176, 75 (2003)

2. P. C. Andricacos, Electrochem. Soc. Interface, 8, 32 (1999).

3. V. S. Donepudi, R. Venkatachalapathy, P. O. Ozemoyah, C. S. Johnson, and J. Prakash, Electrochem. Solid-State Lett., 4, C13 (2001).

4. A. E. Braun, Semicond. Int., 22, 58 (1999).

5. W.-P. Dow, M.-Y. Yen, C.-W. Chou, C.-W. Liu, W.-H. Yang, and C.-H. Chen, Electrochem. Solid-State Lett., 9, C134 (2006).

6. K. Tagaki, H. Honma, and T. Sasabe, IEEE Electr. Insul. Mag. (USA), 19, 27 (2003).

7. C. M. Whelan, M. R. Smyth, and C. J. Barnes, J. Electroanal. Chem., 441, 109 (1998).

8. A. Kudelski, M. Janik-Czachor, J. Bukowska, M. Dolata, and A. Szummer, J. Mol. Struct., 482/483, 245 (1999).

9. C. E. Täubert, D. M. Kolb, U. Memmert, and H. Meyer, J. Electrochem. Soc., 154 D293 (2007).

10. W.-P. Dow, H.-S. Huang, M.-Y. Yen, and H.-H. Chen, J. Electrochem. Soc., 152 D77 (2005).

11. J. J. Kellya and A. C. West, Electrochem. Solid-State Lett., 2, 561 (1999).

12. M. Hasegawa, U. Nonaka, Y. Negishi, Y. Okinaka, and T. Osaka, J. Electrochem. Soc., 153, C117 (2006)

13. V. A. Vas'ko, I. Tabakovic, and S. C. Reimer, Electrochem. Solid-State Lett., 6, C100 (2003).

14. S. Ahmed, D. N. Buckley, S. Nakahara, T. T. Ahmed, and Y. Kuob, J. Electrochem. Soc., 154, D103 (2007).

15. S. Nakahara, S. Ahmed, and D. N. Buckley, Electrochem. Solid-State Lett., 10, D17 (2007).

16. G. R. Stafford, M. D. Vaudin, T. P. Moffat, N. Armstrong, V. D. Jovic, and D. R. Kelley, in Electrochemical Technology Applications in Electronics III, C. Madore, T. Osaka, L. T. Romankiev, and Y. Yamazaki, Editors, Vol. 99-34, p. 340, The Electrochemical Society Proceedings Series, Pennington, NJ (1999).

17. J. Reid, C. Gack, and S. J. Hearne, Electrochem. Solid-State Lett., 6, C26 (2003).

18. D. P. Tracy and D. B. Knorr, J. Electron. Mater, 22, 611 (1993).

19. A. Vicenzo and P. L. Cavallotti, J. Appl. Electrochem., 32, 743 (2002).

20. B. Ke, J. J. Hoekstra, B. C. Sison, and D. Trivich, J. Electrochem. Soc., 106, 382 (1959).

21. G. R. Stafford, M. D. Vaudin, T. P. Moffat, N. Armstrong, V. D. Jovic, and D. R. Kelly, Proc.-Electrochem. Soc., 99, 340 (2000).

22. Z. V. Feng, X. Li, and A. A. Gewirth, J. Phys. Chem. B, 107, 9415 (2003)

23. W.-P. Dow, M.-Y. Yen, W.-B. Lin, and S.-W. Ho, J. Electrochem. Soc., 152, C769 (2005).

24. V. A. Vas'ko, I. Tabakovic, S. C. Reimer, and M. T. Kief, Microelectron. Eng., 75, 71 (2004).

25. S. Nakahara, Thin Solid Films, 64, 149 (1979). 